heated at $95^{\circ} \mathrm{C}$. for $4 \mathrm{hr}$. in the presence of excess concentrated hydrochloric acid to dissoc:ate the iron chelates and form the amino-acid dihydrochlorides. The solid hydrochlorides were washed several times with concentrated hydrochloric acid to remove the iron chloride, then made $p H 3 \cdot 5-4 \cdot 0$ with $1 N$ sodium hydroxide to form the free acid. Each fraction was filtered, washed with water until the filtrate was free of chloride, then dried under vacuum. 'The dry freeaeid fractions were analysed spectrophotometrically by an iron increment addition method similar to that of Hill-Cottingham ${ }^{3}$. The results are given in Table 1.

$$
\text { Table } 1 .
$$

$$
\begin{array}{lcc} 
& \text { Weight (gm.) } & \text { Purity (per cent) } \\
\text { LHPG from violet iron chelate } & 0.7130 & 90 \cdot 0 \\
\text { EHPG from brown iron chelate } & 1.4752 & 98.9
\end{array}
$$

Paper chromatograms of the iron chelates of these separated isomers yielded only one spot in each case. Complete visible absorption speetra of aqueous solutions of the iron chelates were identical with reported spectra ${ }^{1,2}$, except for a slight difference in the wave-length of maximum absorption. The maximum absorption of the violet chelate oecurred at $485 \mathrm{~m} \mu$ whereas that of the brown chelate occurred at $475 \mathrm{~m} \mu$. The reported wave-length of maximum absorption of the iron chelate of unseparated EHPG and that found in this laboratory with tho starting material was $480 \mathrm{~m} \mu$. Attempts to determine which separated isomer was the $d l$-racemic mixture by resolution of the free acid using strychnine, brucine and amphetamino were unsuccessful.

An experiment to demonstrate any significant difference in the abilities of these isomers to trans. locato iron to bean plants growing in alkalino soil was conducted. To $0.246 \mathrm{~m}$.moles of each isomer was added $0.224 \mathrm{~m}$.moles of ferric chloride containing $20 \mu \mathrm{c}$. of iron-59. The $p \mathrm{H}$ was adjusted to $5-7$ with sodium hydroxide and the resulting solutions were diluted to $50 \mathrm{ml}$. with water. Two $20-\mathrm{ml}$. aliquots of each solution were mixed with $500 \mathrm{gm}$. of alkaline Utah soil $(p \mathrm{H} 8 \cdot 4)$, and five bean seeds were planted in each pot. Fourteen days after planting, the bean plants were thinned out to leave two plants in each pot. Twenty-seven days after planting the primary leaves of the remaining two plants in each pot were removed, dried and ground. The uptake of iron was determined by counting a known weight of leaf sample using a well-type scintillation counter and comparing this count with that obtained from an aliquot of the original iron-59 solution. The results are given in Table 2.

$\begin{array}{lcc} & \text { Table 2 } & \\ \text { Violet iron chelate } & \text { Iron (p.p.m.) } & \text { Average } \\ & 96.0 & 90 \cdot 5 \\ \text { Brown iron chelate } & 85 \cdot 0 & \\ & 68.9 & 77.6 \\ & 86.2 & \end{array}$

The small difference in average iron uptake is within expected variability among plants in an experiment of this size. Thus both forms of EHPG are effective in translocating iron to bean plants grown in alkaline soil.

DANiEL P. Ryskifwich George BoKa

Geigy Research Laboratories,

Division of Geigy Chemical Corporation, Ardsley, New York.

${ }^{1}$ Kroll, H., Knell, M., Powers, J., and Simonian, J., J. Amer. Chem. Soc., 79,2024 (1957).

2 Frost, A. E., Freedman, H. H., Westerback, S. J., and Martell, A. E., J, Amer. Chem. Soc., 80, 530 (1958).

${ }^{3}$ Hill-Cottingham, D. G., Analyst, 82, 524 (1957). (1960).
(12ubin, M., and Princiotto, J. V., Ann. N.Y. Acad. Sci., 88, 450

\section{Some Chemical Reactions of Sulphur Hexafluoride}

SULPHUR hexafluoride has customarily been considered to be chemically inert. It is unaffected by aqueous or fused alkali, ammonia or oxygen. The earliest report ${ }^{1}$ states that sulphur hexafiuoride is reductively degraded by sulphur and selenium vapours, and hydrogen sulphide at olevated temperatures, but these reactions have never been reinvestigated. The only substantiated chemical reaction of sulphur hexafluoride is that with a hot alkali metal, reaction with a film of sodium commencing at $200^{\circ}$. The great stability of sulphur hexafluoride is kinetic rather than thermodynamic in origin since it is thermodynamically unstable with respect to water ${ }^{3}$. The inability of nucleonhilic reagents to attack the su'phur hexafluoride molecule can be ascribed to their failure to form an $\mathrm{S}_{\mathrm{x}_{2}}$ typo transition state because the sulphur atom has no orbital of sufficiently low enorgy to permit its coordination with the unshared electron pair of the entering nucleophile. Attack by a nuclcophilic reagent on a fluorine atom of sulphur hexafluoride is improbable for the same reason. However, there still remains the possibility of reaction with an olectrophilic reagont, for example, a strong Lewis acid, the transition state of which is formed by co-ordination of the reagent with a fluorine atom using one of its lone electron pairs. This possibility does not appear to have been investigated until now.

The reaction of sulphur hexafluoride with several 'fluorophilic' Lowis acids has now been investigated. We have found that it is reductively degraded by anhydrous aluminium chloride at moderate tem. peratures. 'Thus when the reactants were heated together in a sealed glass ampoule at $180-200^{\circ}$ for $24 \mathrm{hr}$. a 15 per cent conversion to aluminium fluoride (identified by X-ray powder photography) occurred with the concomitant formation of chlorides of sulphur and chlorine. No compound containing sulphur and fluorine other than unchanged sulphur hoxafluoride was found among the reaction products.

Using published thermodynamic data ${ }^{4,5}$ it can bo shown that a reaction between sulphur hexafluoride and sulphur trioxide is thermodynamically feasible:

$$
\mathrm{SF}_{6}+2 \mathrm{SO}_{3} \longrightarrow 3 \mathrm{SO}_{2} \mathrm{~F}_{2}: \Delta G^{298^{\circ}}=-136 \mathrm{kcal} \text {. }
$$

We have found that such a reaction occurs when the reactants are heated together in a sealed glass ampoule at $250^{\circ}$ for $24 \mathrm{hr}$. A 20 per cent conversion to sulphuryl fluoride (identified by infra-red spectroscopy) was found undor these conditions; a trace of silicon tetrafluoride was the only other product. This is the first reaction of sulphur hexafluoride observed in which the hexavalent state of the sulphur is retained in the products.

No reaction was detectable between sulphur hexafluoride and boron trichloride at temperatures up to $200^{\circ}$.

$$
\begin{aligned}
& \text { J. R. CASE } \\
& \text { F. NyMAN }
\end{aligned}
$$

Imperial Chemical Industries, Ltd., Research Department,

Alkali Division, Northwich, Cheshire.

${ }^{1}$ Moissan, H., and Tebeau, P., C.R. Acad. Sci., Paris, 130, 869 (1900).

"Cowen, H. C., Riding, F., and Warhurst, E., J. Chem. Soc., 4168 (1953).

${ }^{3}$ Roberts, H. L., Quast. Rev. Chem. Soc., 15, 30 (1961).

${ }^{4}$ Gross, P, Hayman, C., and Levi, D. L., Intern. Symp. Fluorine Chemistry, Birmingham (1059).

s National Bureau of Standards. Cirr. 500. 